umbilicus being unfolded and the patient being unable even to sit down with comfort. Large veins were visible over the swelling and the skin was stretched to what looked like the cracking point. The patient was emaciated and she looked haggard and had an anxious expression. Breathing and movement were alike impeded and painful. She had come from a village 14 miles away, but the idea of staying at the hospital proved so objectionable to her that she returned to her home. In a week she came back again begging to be admitted. She was in great distress, could scarcely breathe, and movement was all but impossible. The abdomen was apparently larger than before. "The fulness extended to, and filled out, the flanks and went down to the pelvis so that it stood ont from the lower ribs which were pressed ont and hung over the pelvic bone. The tension was so great that no organs could be palpated. The heart was displaced; the apex beat was heard best in the second space three and a half inches from the mid-sternal line. The lungs on percussion were found to be squeezed into a contracted space at the upper part of the thoracic cavity. From the third rib downwards it was not possible to distinguish lung sounds as the tumour occupied the whole space. The pulse was running and weak and the patient was too ill for any exhaustive examination to be made. She was in such distress that a preliminary tapping was done and four quarts of a greenish-yellow slimy fluid were withdrawn. Unfortunately this was thrown away before examination. The vaginal vault was found to be bulging downwards and full; and the uterus was pushed down, but was normal. No other organs could be distinguished. Dr. Jenny C. Müller of St. Stephen's Hospital, Delhi, was called in, in consultation, and a laparotomy was decided upon, the provisional diagnosis of ovarian cyst having been made.

Four hours after tapping the abdomen was full and taut again. On the next ajy the patient, having been duly prepared and presenting a more favourable condition with a slightly better pulse, was operated upon. The ordinary incision was made in the abdominal wall. When the skin and fascia, \&s., had been divided it was found impossible to pick up and to divide the peritoneum. Indeed, the usual appearance of the peritoneum was not to be seen. Instead, a thin dull layer closely adherent to a thick tough wall was found. It was not possible to separate the two, so the thick wall was incised. It was at least a quarter of an inch thick and very tough. Its inner surface was rugose. On incision a large quantity of the greenish-yellow glairy fluid escaped. On inserting a hand into the cavity thus opened several round tumours were encountered. They were slimy balls filled with a transparent opalescent fluid. They varied in size from that of a pin's head to the dimensions of a football. They occupied the cyst from the level of the third rib down into the pelvis. The cyst contained several pockets separated from each other by strands of connective tissue which were broken down with difficulty. 200 cysts were counted and at least as many more were found burst or escaped in the fluid used to wash out the cavity. The burst ones had their walls rolled up in scrolls and were in some cases packed away under the bigger cysts. The walls were slimy and transparent and varied in thickness with the size of the cyst. The bigger cysts showed danghter and grand-daughter cysts. On the lining membrane were found scolices on subsequent microscopic examination. The fluid was opalescent and had a faint odour. It took some time to empty all the pockets, as they were up in the thorax and against the posterior wall. An attempt to separate the peritoneum from the thickened cyst wall was unsuccessful, nor was it possible to determine the seat of origin of the cyst, though the liver was suspected. The cavity was well washed out with saline solution and a drain left in in the lower part of the wound. In two days the heart came down and the apex beat was heard and felt in the fourth space; gradually the other organs resumed their usurped positions. The cavity was washed out daily with saline solution and a drain left in. At first this was a long tube, later a gauze drain was sufficient. Three weeks after the operation the patient had a rise of temperature, following on a couple of days of malaise. The wound had an unpleasant sweetish odour. In the daily dressing another cyst was found and evacuated. It came from the left lobe of the liver. The patient improved steadily till five weeks later, when she had a similar rise of temperature with extreme tenderness in the region of the left lobe of the liver. Her breath had a sweet "apple" odour and the wound smelt the same. A srilliant green pus exuded from the wound. On microscopic examination this showed the bacillus pyocyanus. As saline solution alone was used for ber daily irrigating and an iodoform dressing applied it was found impossible to account for this. She was put on alkalies and improved rapidly; the wound was cleaned out. The cavity continued to diminish in size. Four months after the first operation a second was done as white cyst-wall material was seen in the discharging sinus. This was scraped. The patient then improved without a break. She was given hæmatogen for a time but soon was in such splendid condition that she was able to do without it. The cavity closed entirely, the patient put on flesh rapidly, and went home looking 20 instead of 50 as she did on admis. sion. She came from a village and described her hut and surroundings as being occupied by dogs, sheep, and cattle, as well as her family. The open stream from which they got their water was common to men and beasts. Delhi.

\section{SUDDEN AND COMPLETE INVERSION OF THE UTERUS : ITS PROBABLE CAUSATION.}

\section{BY ARTHUR MAUDE, M.R.C.S. ENG., L.R.C.P. LOND.}

Complete inversion of the uterus is so rare that its occurrence justifies notice and some remarks on the subject. I was hastily summoned to a young woman in labour of her third child. The so-called " midwife" in attendance realised that something serious had happened but had no idea of its nature and thought that the patient was dead. She was nearly so, having no pulse at the wrist and being in a state of almost complete unconsciousness from shock. There had been very severe hæmorrhage but it had almost ceased when I arrived. The uterus was completely inverted, lying quite outside the vulva. The cord had been separated near the umbilicus but was not abnormally short. The woman was in such a pool of blood that it was not easy to realise what bad happened in a few seconds: the point that gave me the clue at once was the feel of the round ligaments on each side, which were dragged right down to the most external part of the uterus, which was the fundus, capped by the placenta. Two important points I noted without at the time realising their importance. First, that the cord was thin and frail; if traction had been made on the cord sufficiently powerful to invert the uterus it is probable that it would have broken close to its placental attachment; this it had not done and I regard its condition as better evidence that undue traction had not been employed than the statement made (in answer to my questions) by the midwife that she had not employed it. Secondly, the polar position of the placenta was absolnte; the placenta lay attached to the inverted fundus as if it had been placed by design in the axis. This observation is confirmatory of the view expressed by Hennig ${ }^{2}$ many years ago that the active cause of this disaster is an absolutely polar attachment of the placenta.

The history of this case as given by the midwife and afterwards by the patient was that the labour had been quite natural and rather rapid. There was no straining effort or unusual position assumed by the mother during labour. Both women agreed that the child, which presented head first, was born rapidly at the last and that the placenta and uterus came out together immediately after it. I found the placenta very large and adherent except at the edges; so, considering the very grave condition of the woman and thinking that she would stand no prolonged manipulation, I decided not to try to reduce the placenta with the uterus but to risk its detachment. I peeled it off with the left hand, gently reduced the axis of the fundus first, and. fortunately, restored the whole organ withont difficulty. Having a very small hand I followed the fundus up and kept my hand in the cavity till good contractions began to become constant, which was after about ten minutes; during this time and for three hours after I kept up massage through the abdominal wall. Probably not more than a quarter of an hour had elapsed between the inversion and my arrival and dealing with it. Hence I found the spasm of the inverted ring of Bandl very slight and the ease of reduction proportionate. There was no serious amount of bæmorrhage after the uterus was restored to its proper position. It is unnecessary to detail the treatment for shock and loss of blood employed.

1 Ueber die Ursachen der Spontanen Inversio Uteri, Archiv für Gynäkologie, Band vii., p. 491. 
The value of this case depends on the points to which attention has been directed; the inversion was complete; the position of the placenta and its large size, coupled with the absence of evidence of artificial production, tend to support the theory of Hennig to which reference has been made. The patient made an excellent recovery and there was no tendency to secondary chronic inversion.

Complete inversion of the uterus is extremely rare. Braun had never seen a case in 150,000 births. In Ramsbotham's tables of 50,000 births the accident is not even mentioned, and it seems doubtful if in 1847 it had even been recognised. From 1745 to 1880 at the Rotunda in 191,000 deliveries it had only once been observed.

Westerham.

\section{ON BLOOD COAGULABILITY IN THE PUERPERAL STATE.}

BY R. HINGSTON FOX, M.D. BRUX., M.R.C.P. LOND., PHYSICIAN TO THE FRIENDS' PROVIDENT INSTITUTION.

THE object of this paper is to reccrd observations made on the coagulation time of the blood in the puerperal condition. The observations were made by Wright's method, modified by the author, and a correction has been introduced for temperature.

Method.-Sir A. E. Wright's apparatus is described and figured in THE LANCE' of Oct. 14 $\mathrm{gh}, 1905, \mathrm{p} .1096$. I have after experience dispensed with the mercury, the segmentation of the tube, and its hair-fine tapering end, and the method used by me is as follows:-

The apparatus consists of a series of capillary tubes, eight centimetres in length, and each of such calibre that five cubic millimetres of mercury fill it to the length of five centimetres; each tube is inserted, the smaller end outwards, into a short larger tube and fixed in its place in an air-tight manner by sealing wax. Rubber nipples to fit the tubes, a beaker of water standing on white paper, a spirit lamp, an accurate thermometer, and a piece of string are provided. Four of the tubes are taken in succession and nearly filled with blood from a puncture near the end of the finger or thumb. Care should be taken that the blood flows freely, as squeezing the finger is apt to cause lymph from the tissues to be mixed with the blood, leading to an incer for mer oe ligatured, as this much lessens the coagulation period. The blood lying in the tube should not quite reach either end of it. Each tube as soon as filled is laid on the table in order by the side of the thermometer and the exact time of drawing the blood from the finger noted on paper. The finger is then wiped and the puncture closed until after an interval of 30 seconds or more the next tube is applied and the time noted. When all four tubes have been filled the observer decides at what interval he will examine the first tube, com mencing well under the expected coagulation period. A rubber nippl is applied and the blood in the tube expressed into the water. If the mass is readily diffused the next tube may be left for one or two minutes longer than the first. The process is repeated until either a defined wormlike clot is expelled, which retains its form for some seconds, or until the contents have become so dense that they are with difficulty expressed. This occurs in some cases apart from the formation of a red wormlike clot, the mass being partially diffusible in the water. The reason of this variation is probably the admixture of coagulable lymph. At present I reckon the coagulation time to be the time which elapses before either a wormlike clot is formed or else the tube is with difficulty emptied, whichever happens first. Should the nipple fail to expel the contents the string should be wound tightly around the lower part of the nipple and then persistent efforts in com pressing it will generally succeed in emptying the tube. If this cannot be done the tube must be discarded.
cleansing a tube when once choked.

Sir A. E. Wright accounts the coagulation time to be com pleted before the first appearance of a shred of fibrin forma tion. This appearance is seen much earlier and I think may sometimes be accidental, due to the presence of a minute quantity of blood less freshly drawn or of skin tissue or other extraneous matter. It seems to me better to wait until the entire mass of blood is coagulated. As by this means we obtain a much longer coagulation period than Sir A. W. Wright's the figures are not comparable with his.

Correction for temperature.-Five observations in immediate succession were made on a healthy man, aged 22 years, whose pulse was 72 , regular; arterial pressure 100 degrees (Hill and Barnard). The blood was known to have an over-average coagulation time. The tubes when willed with blood were placed in small test tubes, weighted with mercury, and plunged into a water bath of a capacity of about two litres. The water was maintained at a given temperature-viz., $40^{\circ}, 50^{\circ}, 60^{\circ}, 70^{\circ}$, and $80^{\circ} \mathrm{F}$. respectively-in the five observations. It had previously been ascertained that the temperature of the air within the test tubes at several readings accorded closely, in each case, with the temperature of the water in the bath. The follow-

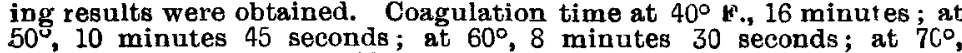
7 minutes 30 seconds; at $80^{\circ}, 6$ minutes 40 seconds. On plotting thes' out to scale the coagulation time is seen to form a curve, the ordinates of time increasing greatly as the temperature descends towards freezing point, to which liue the curve doubtless forms an asymptote. A curve has been found which closely approximates to this between the temperatures $40^{\circ}$ to $80^{\circ} \mathrm{F}$., but I have not yet obtained a formula for reducing observations to the standard temperature of $60^{\circ}$. This correction must therefore be made from the diagram graphically.

Observations on blood ooagulability in the puerperal state.By the kindness of Dr. W. J. Gow, physician to Queen Charlotte's Lying-in Hospital, I have made observations on the blood of eight parturient women during the first week after delivery in the wards of that hospital. All were primiparæ ; unmarried, except the patients in Cases 2 and 8 ; the labours were normal, but in Cases $1,3,5,7$, and 8 they were tedious ; hæmorrhage was normal; all suckled their infants, who appeared to be healthy. In Case 4 there was a trace of albuminuria and the temperature rose to $100 \cdot 2^{\circ} \mathrm{F}$. on the second day, the pulse-rate being 108 ; milk on the fifth day was rather deficient. Gonorrhcea was present in Case 1 . The observations were taken between the hours of 2.30 and 6 P.M. The patients were, of course, recumbent in their beds. The results, corrected for temperature, are as follows, the period required for complete coagulation being represented in minutes :-

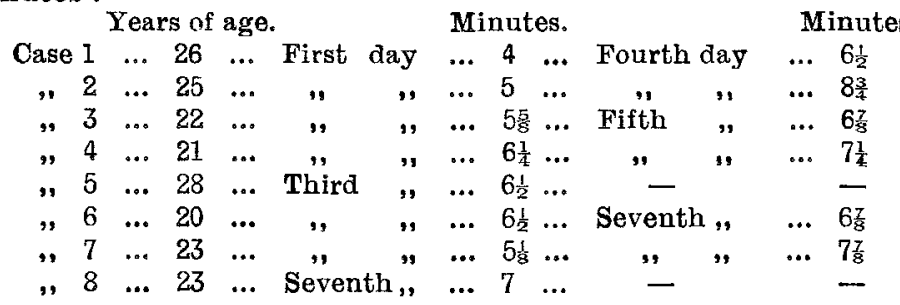

The observations may also be summarised as under :-

$$
\begin{aligned}
& \text { First day } \quad \ldots \quad \text { Four observations } \quad \ldots \quad 4,5,5 \frac{5}{8}, 6 \frac{1}{4} \text { minutes. } \\
& \text { Third day ... Three } \quad, \quad \ldots 6 \frac{1}{2}, 6 \frac{1}{2}, 5 \frac{1}{8} \\
& \text { Fourth day ... Two Two \# } 6 \frac{1}{2}, 8 \frac{3}{4} \\
& \begin{array}{llllll}
\text { Fifth day } & \ldots & \text { Two } & \quad \text { Two } & \ldots & 6 \frac{7}{8}, 7 \frac{1}{4}
\end{array} \\
& \text { Seventh day... Three } \quad ", \quad \ldots \quad 7,6 \frac{7}{3}, 7 \frac{7}{8}
\end{aligned}
$$

Comparing these figures with many other observations taken by the same method I find that the coagulation time immediately after delivery is below the normal but not to the same extent as is commonly supposed. For I have often found a much lower coagulation time in adults, as low as three minutes or less. Five and a quarter minutes, the average time on the first day after confinement, is not therefore very low. Perhaps under the careful management of labour in the hospital the hæmorrhage is less, and so the blood coagulability is less altered on this account. It will be noticed that in every case in which two successive observations were taken the coagulation time had increased during the interval. The excretion of calcium salts in the milk tending to reduce the coagulability of the blood was probably one cause of this increase.

An observation of the coagulation time of the blood after delivery might give useful warning : of the risk of thrombosis or embolism if the coagulation time were low, or of postpartum hæmorrhage if it were high. Appropriate treatment - for example, with citric acid on the one hand or with calcium lactate and salines on the other-would rectify the condition.

I made a few observations on some of these women during the latter part of pregnancy and subjoin them for what they are worth. So far as they go, they indicate a tendency to a low coagulation time, in several cases lower than after delivery. ${ }^{1}$ The blood during pregnancy is probably rich in nutrient matter required for the growth of the foetus. According to Winckel, it has a somewhat diminished alkalescence and exhibits a more ready (mässige) leucocytosis. Bar and Daunay state that the density of the blood is diminished at the end of pregnancy but rises again after partus. My observations of the coagulation point were made under various conditions as to time of day and relation to exercise and to meals, contrasting with the even conditions attaching to those made in the wards of the hospital. Observations on the Same Cases during Pregnancy.

$$
\begin{aligned}
& \text { Case } \begin{array}{llllllll}
1 & \ldots & \ldots & 11 & 1 \text { days before partus } & \ldots & \ldots & 4 \frac{1}{4} \text { minutes. }
\end{array}
\end{aligned}
$$

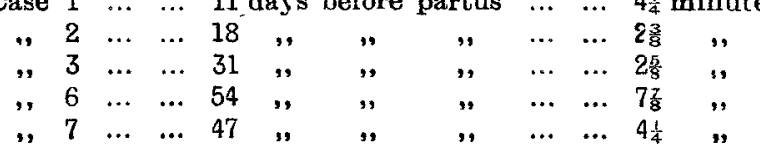

I have not found any reference to the coagulability of the blood in pregnant or puerperal states in recent works on obstetrics, British, French, or German.

Weymouth-street, W.

1 Compare Dr. Blair Bell's reference to the presence of large quantities of calcium salts in the systems of pregnant women, Brit. Med. Jour., April 20 th, 1967 , p. 921 . 